\title{
Comparison of intravenous edrophonium and oesophageal acid perfusion during oesophageal manometry in patients with non-cardiac chest pain
}

\author{
J S DE CAESTECKER, A PRYDE, AND R C HEADING
}

From the Department of Medicine, Royal Infirmary, Edinburgh

SUMmary Sixty consecutive patients referred for evaluation of non-cardiac chest pain had oesophageal manometry. Motility was assessed basally, after edrophonium $80 \mu \mathrm{g} / \mathrm{kg}$ iv and during oesophageal perfusion with $0 \cdot 1 \mathrm{~N} \mathrm{HCl}$ at 6 and $14 \mathrm{ml} / \mathrm{min}$ for eight and seven minutes respectively. A positive response, defined as symptom reproduction with or without abnormal motility, was present in 21 patients $(35 \%)$ after acid perfusion and $12(20 \%)$ after edrophonium. Eleven of the 12 patients responding to edrophonium also responded to acid perfusion, including most of the patients with primary motility disorders. Significantly greater increases in peristaltic duration, but not amplitude, were recorded after edrophonium $(p<0.01)$ and acid perfusion $(p<0.05)$ in positive responders, compared with non-responders. Results indicate that acid perfusion during oesophageal manometry may be a more useful stress test than edrophonium and that the mechanism of symptom production may be similar.

Oesophageal motor disorders, including gastrooesophageal reflux, may be shown in up to $60 \%$ of patients with recurrent non-cardiac chest pain.'? Conclusive evidence that such abnormalities are relevant requires the concurrence of symptoms. ${ }^{2-4}$ Exercise ECG testing is well established as a stress test in the investigation of angina pectoris resulting from ischaemic heart disease, but no comparably simple and reliable stress test exists for the oesophagus. Oesophageal acid perfusion identifies acid sensitivity and is generally considered to be a means of showing an oesophageal origin for chest pain. ${ }^{5-7}$ Acid sensitivity is not the same as acid gastrooesophageal reflux, although in practice the two often coexist. ${ }^{84}$ The situation with primary motility disorders of the oesophagus is more difficult and much investigation has attempted identification of a satisfactory provocation test to elicit abnormal motility and allow demonstration of its coincidence with the occurrence of pain. ${ }^{111-1+1}$ Intravenous edrophonium has recently been advocated for this purpose. ${ }^{1.314}$

Although it is well accepted that acid perfusion

Address for correspondence: Dr J S de Caestecker, Ashford Hospital, London Road, Ashford, Middlesex.

Received for publication 12 February 1988. may establish an oesophageal cause for chest pain, its value as an adjunct to manometry is uncertain. Based on these considerations, we have examined symptom provocation and oesophageal motility in response to oesophageal acid perfusion and intravenous edrophonium in a group of patients with recurrent non-cardiac chest pain.

\section{Methods}

PATIENTS

We studied 60 consecutive patients with recurrent chest pain thought to be non-cardiac in origin. All were referred to our unit for oesophageal function tests. Twenty one were men, and 39 women, with a mean age of 50 years (range 18-70). Forty nine were referred after assessment by cardiologists. Eighteen patients described pain of anginal type, while $42 \mathrm{had}$ chest pain which was atypical in character, duration and precipitating factors. Cardiac disease was excluded as follows: 16 of 18 patients with anginal pain had negative exercise ECGs. Six had normal ECGs during prolonged spontaneous rest pain. Eleven, including the two with positive or equivocal exercise tests, had normal coronary arteriography. Of the $\mathbf{4 2}$ with atypical pain, 10 had normal coronary arterio- 
grams, 16 negative exercise ECGs (including four with normal 24 hour ambulatory ECG records and three with normal ECGs during spontaneous pain), 10 had normal ECGs during spontaneous pain, and two had normal 24 hour ambulatory ECG records despite symptoms. Two patients had significant $(>50 \%)$ coronary stenosis at angiography, but both had negative exercise ECGs, exercise isotope ventriculography and 24 hour ECG records. Finally, two patients did not have formal cardiac evaluation, but also had major presenting symptoms of dysphagia and odynophagia.

Oesophageal symptoms occurred in 36 , including dysphagia (15), odynophagia (11), heartburn and/or acid regurgitation (34). Of the 34 with heartburn and/ or acid regurgitation, however, symptoms were only elicited by direct questioning in 30. In 12 of these symptoms were very infrequent (<once a month) and were infrequent (once a week or less) in the remaining 18.

All patients initially underwent either endoscopy (49) or a barium swallow and meal examination (11) Findings including oesophagitis (nine), duodenitis (two), and gastric ulcer (two). In the case of the latter two, specific therapy resulted in ulcer healing, confirmed endoscopically, without remission in the patients' symptoms.

Oesophageal manometry was done using an eightchannel oesophageal catheter coupled to a low compliance constant water perfusion pump (Arndorfer Specialties Inc, Greendale, Wisconsin, USA). The manometric technique used has been previously described. ${ }^{2}$ Briefly, patients were examined supine, and the lower oesophageal sphincter (LOS) pressure determined by the rapid pull through technique. Distal oesophageal motility was assessed using recording channels 3,10 , and $15 \mathrm{~cm}$ above the LOS in response to 15 swallows of $5 \mathrm{ml}$ water administered at 20 second intervals. Edrophonium $80 \mu \mathrm{g} / \mathrm{kg}$ was then administered intravenously and for the next five minutes distal oesophageal motility was assessed as described above. The occurrence of pain replicating the patient's typical symptoms was regarded as a positive test, although transient twinges of pain lasting a few seconds only were ignored.

Ten minutes after edrophonium injection, oeso- phageal acid perfusion with $(0 \cdot 1 \mathrm{~N} \mathrm{HCl}$ was carried out through channels 5 and $20 \mathrm{~cm}$ above the LOS at rates of $6 \mathrm{ml} / \mathrm{min}$ for the first eight minutes, and at 14 $\mathrm{ml} / \mathrm{min}$ for a further seven minutes. A positive test consisted of replication of the patient's typical symptoms which persisted while perfusion continued. Transient twinges of pain were ignored, and burning retrosternal pain, unless accompanied by the patient's usual pain, was regarded as a negative result. At the onset of symptoms, or, if no symptoms occurred, after 10 minutes, motility was reassessed in response to wet swallows as described above.

The last 22 patients had 12 lead ECGs carricd out before the provocation manocuvres, and during symptoms (if this occurred).

Subsequent to the motility studies, the patients underwent 23 hour ambulatory $\mathrm{pH}$ monitoring of the distal oesophagus using a combined glass electrode and reference electrode (Radiometer no GK 2801C) passed by the naso-oesophageal route and positioned to lie $5 \mathrm{~cm}$ above the LOS. The electrode was connected to a portable digital recorder worn by the patient on a belt (Digitrapper, Synetics Ltd). During the recordings, patients were encouraged to remain freely ambulant during the daytime, and no restrictions were placed on diet or activities. Each patient recorded the time and composition of food or drink ingestion, together with the time of retiring to bed and of symptom occurrence. One patient refused the test, and in three others the recording was unsatisfactory for technical reasons, so that 56 studies were completed. Before and after each study, the $\mathrm{pH}$ probe was calibrated against a range of buffers to exclude drift. The recorded data were stored on floppy disc for later replay and analysis by computer.

\section{INTERPRETATION OF RESULTS}

Average amplitude ( $\mathrm{mmHg}$ ) and duration (seconds) of the last five peristaltic waves after wet swallows during the basal study, the first five after edrophonium and five waves either during symptoms or 10 minutes after the start of acid perfusion were calculated using the record from the most distal manometric channel.

Abnormality was classified using the system described by Benjamin and colleagues, ${ }^{13}$ modified

Table 1 Number of positive responders to acid perfusion and edrophonium among the patients with abnormal motility

\begin{tabular}{lcccc}
\hline & $\begin{array}{c}\text { High amplitude } \\
\text { Hypertensive } \\
\text { L.OS } \\
\text { (Total 5) }\end{array}$ & $\begin{array}{c}\text { Diffuse } \\
\text { duration peristalsis } \\
\text { (total I0*) }\end{array}$ & $\begin{array}{c}\text { Non-specific } \\
\text { oesophageal } \\
\text { spasm } \\
\text { (Total 2) }\end{array}$ & $\begin{array}{c}\text { oesophageal motor } \\
\text { disorders } \\
(\text { Total 2) }\end{array}$ \\
\hline $\begin{array}{l}\text { Acid perfusion } \\
\text { Edrophonium }\end{array}$ & 0 & 9 & 2 & 0 \\
\hline
\end{tabular}

*Two in association with abnormal gastrooesophageal reflux. Both had positive responses to both edrophonium and acid perfusion. 
according to the values for 50 normal volunteers reported by Nelson and colleagues ${ }^{12}$ using apparatus similar to our own. Patients with normal baseline manometry who developed pain with edrophonium or acid perfusion or both, and in whom average distal peristaltic amplitude exceeded $190 \mathrm{mmHg}$ or exceeded seven seconds in duration were classified as high amplitude and/or prolonged duration peristalsis.

Prolonged $\mathrm{pH}$ monitoring was regarded as showing abnormal acid reflux if the $\mathrm{pH}$ was less than 4 for $>8.2 \%$ of recording time. This value represents the mean +2 SD of results obtained in our laboratory from a group of 15 normal volunteers $(12 \mathrm{men}$, three women, age range 21-66) on an unrestricted diet.

Significant gastrooesophageal reflux was also considered to exist in patients with \% acid exposure within the normal range if typical chest pain coincided with spontaneously observed reflux (this was the case in two patients). Both these patients had a positive acid perfusion test and one had oesophagitis. One further patient with a normal 23 hour $\mathrm{pH}$ study was diagnosed as an abnormal refluxer on the basis of endoscopic crosive oesophagitis.

\section{STATISTICAI. ANAI.YSIS}

Analysis of variance was used for comparisons of peristaltic amplitude and duration during basal recording and after provocation. Increase in peristaltic duration and amplitude were compared between 'non-responders' and 'responders' - that is, positive pain response, using Wilcoxon's rank-sum test, as these data were more skewed. McNemar's test was used to compare the incidence of positive responses after edrophonium and acid perfusion.

\section{Results}

In total, 36 patients $(60 \%)$ were found to have oesophageal abnormalities. Abnormalities detected during baseline manometry included hypertensive lower oesophageal sphincter (five), nutcracker oesophagus (three), diffuse oesophageal spasm (two) and non-specific oesophageal motor disorder (two). Seventeen patients had abnormal gastrooesophageal reflux without motility disorder. A further seven patients, including two with abnormal reflux, developed pain together with high amplitude and/or prolonged duration peristaltic waves in response to acid perfusion and/or edrophonium.

No patient developed symptoms during baseline manometry. One developed symptoms only after edrophonium, 10 during acid perfusion alone and 11 after both tests. A positive response was seen significantly more often during acid perfusion than after edrophonium $(\mathrm{p}<0 \cdot 01$, McNemar's test $)$. A more detailed analysis of type of motility disorder against response to provocation testing is given in Table 1 . Of the 17 patients with abnormal gastrooesophageal reflux but no motility disorder, seven had a positive acid perfusion test. Four of these were also positive to edrophonium. A further three patients with no motility disorder or abnormal gastrooesophageal reflux had a positive acid perfusion test. As we did not control with placebo injection or infusion, we cannot say whether these patients represent true positives or false positive "hyper-reactors".

A positive acid perfusion test occurred in $32 \%$ (11 of 34) patients with symptoms of heartburn and/or acid regurgitation and 38\% (10 of 26) of those without. Three of nine with endoscopic oesophagitis, $59 \%(10$ of 17$)$ with an abnormal 24 hour $\mathrm{pH}$ study and $26 \%$ ( 11 of 43 ) of those with a normal study had a positive acid perfusion test.

None of the 22 patients from whom ECGs were taken during the provocation procedures developed any cardiographic abnormality. Nine of these patients experienced pain; one with edrophonium alone, five with acid alone, and three with both. None of these nine came from the group of 18 with angina like pain.

Peristaltic duration and amplitude increased significantly after edrophonium and during acid perfusion when compared with baseline values in all patients, regardless of response to provocation (Figs 1 and 2).

We compared absolute increase in peristaltic duration and amplitude over basal values after edro-

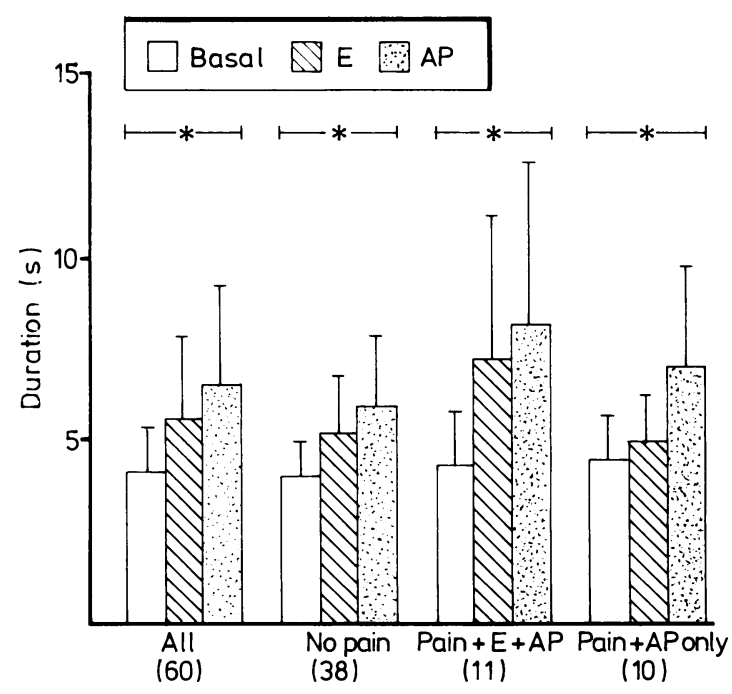

Fig. 1 Mean peristaltic duration $(+S D)$ in seconds during basal manometry, after edrophonium $(E)$ and acid perfusion (AP). Patients are grouped into non-responders, those who responded to acid perfusion and edrophonium, and those who responded to acid perfusion only. ${ }^{*}-p<0 \cdot(0)$ (Analysis of variance). 


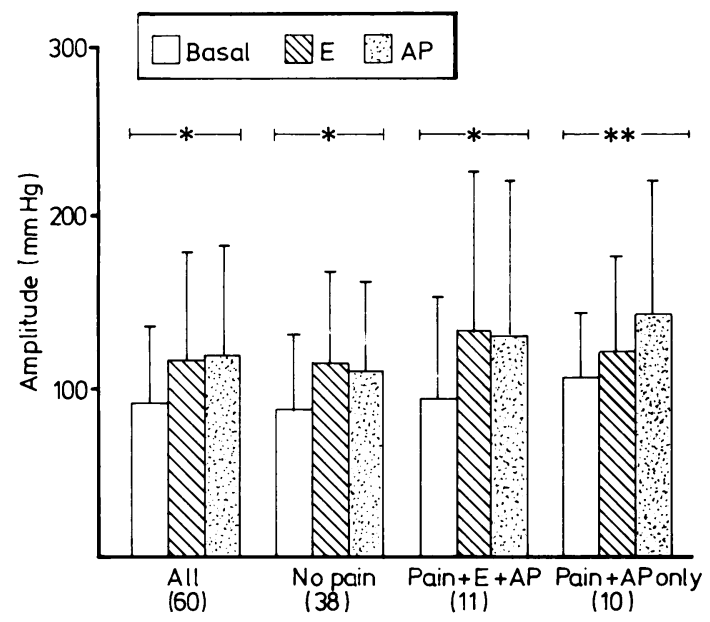

Fig. 2 Mean peristaltic amplitude ( $+S D$ ) in $\mathrm{mmHg}_{\mathrm{H}}$ during basal manometry, after edrophonium $(E)$ and acid perfusion (AP). Patients grouped as for Fig. $I^{*}{ }^{*}-p<0 \cdot 01,{ }^{* *}-p<0 \cdot 05$ (Analysis of variance).

phonium or during acid perfusion (Fig. 3). Patients were divided according to response to each test - that is, edrophonium 12 responders, 48 non-responders; acid perfusion 21 responders, 39 non-responders. There was a significantly greater increase in peristaltic duration, but not amplitude, in responders compared with non-responders after both acid perfusion $(p<0.05)$ and edrophonium $(p<0 \cdot 01$, Fig. 3$)$.

The mean time to development of pain during acid perfusion in patients with motility disorders was five minutes (range $0 \cdot 25-11$ mins) compared with $5 \cdot 5$ minutes (range $0 \cdot 25-15$ mins) in those with gastro-
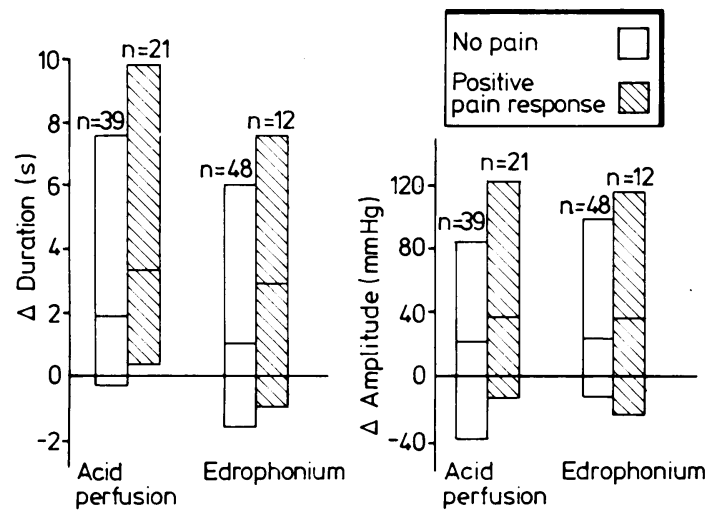

Fig. 3 Changes in peristaltic duration and amplitude (mean and range) after edrophonium and acid perfusion, compared with basal values. Greater increases in mean duration were seen in responders than non-responders both with acid perfusion $(p<0 \cdot 05)$ and edrophonium $(p<0 \cdot 0 I)$ (Wilcoxon's rank-sum test). oesophageal reflux but no motility disorder. This difference was not statistically significant.

\section{Discussion}

Several groups have shown the value of the acid perfusion test in the elucidation of chest pain. ${ }^{5 \text { in } 1 \mathrm{l} / \mathrm{s}}$ Some investigators have shown that patients with a positive acid perfusion test often have independent evidence of gastrooesophageal reflux..$^{89}$ Behar and colleagues found that in a group of 12 patients with chronic chest pain not typical for gastrooesophageal reflux the acid perfusion was positive in all, yet only a minority had evidence of gastrooesophageal reflux. ${ }^{. \mathrm{x}}$ Of our 21 patients with a positive acid perfusion test, nine had abnormal manometry and no evidence of abnormal gastrooesophageal reflux. These findings support the notion that a positive acid perfusion test, particularly in patients with chronic chest pain, denotes acid sensitivity of the oesophagus and does not always imply gastrooesophageal reflux. ${ }^{n 7 \mathrm{ix}}$ Vantrappen's group ${ }^{16}$ 1" had similar findings: some of their patients with chest pain provoked by acid perfusion had symptoms accompanied by abnormal motility but not reflux during subsequent prolonged ambulatory monitoring.

Edrophonium produced a positive response in $20 \%$ of our patients, a similar figure to that found by one group ${ }^{13}$ and a little lower than the figure of about $30 \%$ which has been recently reported. ${ }^{1+20}$ One of these studies," however, was conducted using a considerably higher dose of edrophonium. The other study ${ }^{1+}$ found that acid perfusion was positive in $22 \%$ of their patients, although only $8 \%$ had reproduction of chest pain (the rest experiencing heartburn only which we regard as a negative result in the context of chronic chest pain). Similar results have been reported in a large series from the same group. ${ }^{21}$ The prevalence of positive acid perfusion tests in this study is low $(7 \%)$, as the authors themselves comment. Janssens et al observed reproduction of chest pain during acid perfusion in $27 \%$ of their patients, ${ }^{14}$ a similar proportion to us. We found a positive acid perfusion test in $35 \%$ of our patients, including 11 of the 12 responding to edrophonium. Richter et al ${ }^{14}$ also noted that patients with a positive edrophonium test were more likely to have a positive acid perfusion test; Vantrappen et $a l^{\text {th }}$ have promoted the concept of the 'irritable oesophagus' in this connection. It should come as no surprise that acid perfusion is frequently positive in patients with non-cardiac chest pain, as our prior experience and that of others is that gastrooesophageal reflux is the single commonest abnormality in such subjects. ${ }^{21} 1422$ Although an abnormal 24 hour $\mathrm{pH}$ recording made a positive acid perfusion test more likely, it is interesting that 
heartburn and endoscopic oesophagitis were both poor predictors of a positive acid perfusion test.

Because we did not perform control infusions nor placebo injections, the incidence of false positive results is not known. All but three of our 22 patients with positive responses to one or other of the provocation procedures, however, had either gastrooesophageal reflux showed on $\mathrm{pH}$ studies or abnormal manometry at the time of pain. The positive edrophonium tests in four patients with gastrooesophageal reflux were unexpected. All four were also positive with oesophageal acid perfusion, but we do not know that they would have given negative results with placebo injections or infusions.

Richter et al ${ }^{1+}$ have suggested that the mechanism of symptom induction by edrophonium may be related to prolongation of peristaltic duration. Our results confirm their findings that the increase in peristaltic duration but not in amplitude is significantly greater in patients who develop pain than in those who do not. Similar results were apparent in our patients during acid perfusion, suggesting that there may be some similarity in the mechanism of symptom production. Like Richter's group, we feel that this cannot be the whole explanation, as there is considerable overlap in peristaltic parameters observed in the positive and negative responders, and patients typically experience continuous pain despite the fact that peristalsis is only intermittent. We did observe, however, that in three of our positive responders (to edrophonium and acid perfusion) exacerbation of background pain coincided with giant peristaltic waves.

A possible explanation for the increased peristaltic amplitude and duration seen in response to acid perfusion is that it reflects distension of the oesophagus. ${ }^{232+}$ We might therefore expect that in those with motility disorders, symptoms would develop at the higher rates of perfusion and later during the course of the acid perfusion test, when larger volumes were being delivered. In fact, we found no significant difference in time of onset of pain in patients with motility disorders compared with those with simple reflux and believe it unlikely that this mechanism is a sufficient explanation. Acid perfusion was started 10 minutes after edrophonium injection. Nostrant et al $^{25}$ reported that consecutive doses of bethanecol greatly increase the number of patients developing motility changes and symptoms. We feel that such an interaction in our study is very unlikely because of the very brief duration of action of edrophonium compared with bethanecol. Our experience is that any motility changes after edrophonium have invariably resolved by five minutes after injection.

Previous studies have given conflicting results on whether acid perfusion produces motility changes which are responsible for development of symptoms. Some have found changes in the majority of their patients ${ }^{106}$ other little change. ${ }^{27-2^{29}}$ One study found that a minority do develop marked changes in motility during symptoms. ${ }^{\text {." }}$ Most of these investigations have looked at patients with heartburn and typical symptoms of gastrooesophageal reflux, but

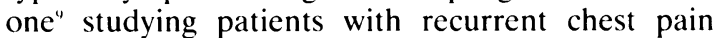
found like us that peristaltic duration was significantly increased compared with controls during acid perfusion.

In conclusion, our findings suggest that the acid perfusion test is a useful adjunct to manometry in patients with recurrent chest pain, and that it may provoke the pain in individuals with primary motility disorders as well as those with simple gastrooesophageal reflux. The acid perfusion test appears to be a more sensitive provocation procedure than intravenous edrophonium and we believe it to be preferable in the investigation of a possible oesophageal origin of recurrent chest pain.

\section{References}

1 Blackwell JN. Castell DO. Oesophageal chest pain: a point of vicw. Gut 1984; 25: 1-6.

2 de Cacstecker JS. Blackwell JN, Brown J, Heading RC. The oesophagus as a cause of recurrent chest pain: which patients should be investigated and which tests should be used? Lancet 1985; ii: 1143-6.

3 Brand DL. Martin D. Pope II. CE. Esophageal manometrics in patients with angina-like chest pain. Dig Dis 1977; 22: 30)-4.

4 Anonymous. Angina and oesophageal disease [Leader]. Lancet 1986; i: 191-2.

5 Bernstein LM, Fruin RC. Pacini R. Differentiation of esophageal pain from angina pectoris: role of the esophageal acid perfusion test. Medicine (Baltimore) 1962; 41: 143-62.

6 Bennett JR. Atkinson M. Oesophageal acid perfusion in the diagnosis of precordial pain. Lancet 1966: ii: 1150-2.

7 Richter JE. Acid perfusion (Bernstein) test. In: Castell DO. Wu WC. Ott DJ, eds. Gastroesophageal reflux disease: pathogenesis, diagnosis, therapy. New York: Futura, 1985: 139-48.

8 Tuttle SG, Bettarello A. Grossman MI. Esophageal acid perfusion test and gastroesophageal reflux test in patients with esophagitis. Gastroenterology 1960); 38: 861-72.

9 Kjellen G, Tibbling L. Oesophageal motility during acid-provoked heartburn and chest pain. Scand $J$ Gastroenterol 1985: 20: 937-40.

10 Orlando RC. Bozymski EM. The effects of pentagastrin in achalasia and diffuse esophageal spasm. Gastroenterology 1970: 77: 472-7.

11 London RL. Ouyang A. Snape WJ, Goldberg S. Hirshfeld JW, Cohen S. Provocation of esophageal pain by ergonovine or edrophonium. Gastroenterology 1981; 81: $10-4$. 
12 Alban Davies H. Kaye MD, Rhodes J. Dart AM. Henderson AH. Diagnosis of oesophageal spasm by ergometrine provocation. Gut, 1982; 23: 89-97.

13 Benjamin SB. Richter JE. Cordova CM. Knuff TE. Castell DO. Prospective manometric evaluation with pharmacologic provocation of patients with suspected esophageal motility dysfunction. Gastroenterology 1983 : 84: 893-901.

14 Richter JE, Hackshaw BT, Wu WS, Castell DO. Edrophonium: a useful provocative test for esophageal chest pain. Ann Intern Med 1985; 103: 14-21.

15 Nelson JL, Wu WC. Richter JE, Blackwell JN, Johns DN. Castell DO. What is normal oesophageal motility? Gastroenterology 1983: 84: 1258.

16 Vantrappen G, Janssens J, Ghillebert G. The irritable oesophagus - a frequent cause of angina-like pain. Lancet 1987; i: 1232-4.

17 Bernstein LM, Baker LA. A clinical test for ocsophagitis. Gastroenterology 1958; 34: 760-81.

18 Behar J. Biancini P. Sheahan DG. Evaluation of esophageal tests in the diagnosis of reflux esophagitis. Gastroenterology 1976; 71:9-15.

19 Janssens J, Vantrappen G, Ghillebert G. 24 hour recording of esophageal pressure and $\mathrm{pH}$ in patients with non-cardiac chest pain. Gastroenterology 1986; 90: 1978-84.

20 Lee CA, Reynolds JC, Ouyang A, Baker L. Cohen S. Esophageal chest pain: value of high-dose provocative testing with edrophonium chloride in patients with normal esophageal manometrics. Dig Dis Sci 1987; 32: $682-8$.

21 Katz PO, Dalton CB, Richter JE, Wu WC, Castell DO.
Esophageal testing of patients with non cardiac chest pain or dysphagia: results of 3 years experience with 1161 patients. Ann Intern Med 1987: 106: 593-7.

22 Demeester TR. O'Sullivan GC. Bermudez D, et al. Esophageal function in patients with angina-like chest pain and normal coronary angiograms. Ann Surg 1982; 196: $488-98$.

23 Dodds WJ. Hogan WJ, Reid DP. Stewart ET, Arndorfer RC. A comparison between primary esophageal peristalsis following wet and dry swallows. $J$ Appl Physiol 1973: 35: 8.51-7.

24 Hollis JB. Castell DO. Effect of dry and wet swallows of different volumes on esophageal peristalsis. $J$ Appl Physiol 1975: 38: 1161-4.

25 Nostrant TT, Sams J. Huber T. Bethanecol increases the diagnostic yicld in patients with esophageal chest pain. Gastroenterology 1986; 91: 1141-6.

26 Siegel CI. Hendrix TR. Esophageal motor abnormalities induced by acid perfusion in patients with heartburn. J Clin Invest 1963; 42: 686-95.

27 Tuttle SG, Rufin F, Bettarello A. The physiology of heartburn. Ann Intern Med 1961; 55: 292-30).

28 Richter JE, Johns DE, Wu WC, Castell DO. Are esophageal motility abnormalities produced during the intra esophageal acid perfusion test? JAMA 1985; 253: 1914-7.

29 Burns TW, Venturatas SG. Esophageal motor function and response to acid perfusion in patients with symptomatic reflux esophagitis. Dig Dis Sci 1985; 30: 529-35.

30 Atkinson M, Bennett JR. Relationship between motor changes and pain during esophageal acid perfusion. $\mathrm{Am}$ J Dig Dis 1968: 13: 346-5(). 